\title{
Multicultural Qualification Necessary for More Qualitative Education for the Roma Community
}

\author{
Msc. Alketa Bulku \\ Vice president at "Bajram Curri" middle school, Tirana, Albania
}

Abstract

\begin{abstract}
Education represents a major challenge and it plays a key role in the social inclusion for the Roma and to their financial background also. The Roma children school attendance level is very law and what they learn from school is not equal to the other children. Poverty, illiteracy and insufficient education lead to a vicious surrounding which sets this community in front of difficulties and marginalisation. According to the law, all people are equal as to the right to education. As a complex approach to equal teaching and studying, multicultural education leads the way to the inclusion of this community within the educational system. Multicultural and inclusive practices improve the quality of the teaching and learning process, considering the chance to reduce barriers. This is a qualitative study which aims at exploring the influence of teachers' qualification on the Roma children engagement at school. The case study is performed through the theoretical study, monitoring, interviews with directors, education specialists and parents and focus groups with parents and teachers. This study presents the teachers, parents and directors' point of view on the importance of the qualification on social justice and the positive influence on teaching. Multicultural practices, less prejudice and education for social justice make school more effective.
\end{abstract}

Keywords: multicultural education, Roma community, teachers' qualification, less prejudice, social justice.

\section{Roma community and problems related to them}

The Roma people are not recognized as a separate minority in Albania; those ethnic communities from existing countries only, have been recognized so. This does not suit for the Roma who do not have a supporting country. The Roma population was recognized as an ethno-linguistic minority by the Albanian Constitution of 1998. Even though, the Albanian Constitution treats the basic principles of humans and minorities rights. "Ethnic affiliation is defined as a subjective feeling of affiliation that can be related to a common culture, language, religion, history, territory, but sometimes none of these characteristics are common, but still in this case we can speak of an ethnic affiliation when referring to the Roma people. According to the World Bank the Roma own clear cultural attributes such as language, music, community celebrations, family ceremonies, artistry and the women's outfit. " The financial structure and size of their families are characterized by a higher number of generations living together and also from a higher number of family members. Usually, the marriage age of the Roma people is lower than the rest of the population, consequently the parental age will be lower and the number of child birth higher, "Current evaluation reports show that the growing rate of the Roma population is $3 \%$, which is higher than the growing rate of the Albanian population".(UNDP, 2011)

Although they possess all these distinguishing characteristics, numerous reasons make this community marginalised and put it face to face to difficulties.

Poverty and low education rates provide them with a vicious environment. Poverty is considered as the main reason why they cannot afford their children's education. The Roma parents consider their children's financial contribution as indispensable because of extreme poverty and unemployment. Extreme living conditions make it impossible for these children to do their homework by becoming the barrier to their good performance at school. Usually, malnutrition leads to lack of concentration during the lesson. The Roma parents are sceptical about their children's ability graduate. Generally, they cannot look after them as they are looking for a job in the market while the oldest child looks after their siblings. According to various studies (Gedeshi, 2010). "Racial discrimination from the other non-Roma children and from teachers" 
represents another reason affecting school attendance. Moreover, another problem would be language and cultural difference. Many Roma children do not know Albanian when they start school, which causes a lot of difficulties to their learning process. This is why they feel obliged to quit school."

Many Roma families are obliged to move from one country to the other because of economic matter. As a result, it is difficult for their children to attend school once they return back to their countries. Regardless of the obstructive factors, the education system bears the responsibility of engaging and involving them within education.

"The main concerning issue is making clear that education is not directly related to employment, neither is it going to soften their poverty." According to the records of Census 2011, 97\% of Albanian children between the ages 6 to 9 years old attend elementary education, while only $55 \%$ of the Roma children of the same age attend school.

These extremely low figures are the result of those who have never been enrolled at school. (INSTAT, 2011)

Self-assessment is not their strong point and this should be a main issue of concern for teachers as they can put the balance between school and the Roma community. But there is still another issue of concern originating from the teachers' prejudice. This can be improved through additional education and trainings for teachers.

In a school where the Roma children make up $40 \%$ of the school children, the ir interviewed parents show no interest against their children's teachers. Only $6 \%$ had asked for their children's old teacher, around $47 \%$ appraised the criteria that teachers must be strict with children as they have not received the proper education during kindergarten and because the parents themselves are unschooled. $75 \%$ of them have attended 0-4 school grades, $25 \%$ have attended elementary school (8 grades school). This is the reason why they cannot help their children and why they do not expect a lot from them.

Parent A says, "I do not know who is going to be his teacher, but I asked the director if it could be the strictest one because he is troublesome. I hope he learns, as we all are unschooled (she meant her family)".

Parent B is sceptic to teachers "I haven't thought about who is going to be the teacher. They are all the same...they do not pay attention to our children, they say - oh you gipsy you don't study". Parent C is sceptic to his child's performance; he tries to find out a reason to make him/her go to school "Can you put him in the young teacher's classroom? This way he can willingly come to school as he is not fond of school".

Parent D speaks about a close connection with his older son which makes him/her hope for the younger as well "Can he please study with the same teacher as my other child as I am used to her, she knows about my misery".

Parent $\mathrm{E}$ does not show any interest at all. "I came to know about his classroom and his teacher the first day I brought my son at school, all teachers are the same".

The average rate of the Roma children aged from 10 to 16 who abandon school reaches $30 \%$ for the boys and $44,6 \%$ for the girls. At $16,96 \%$ of girls and $68 \%$ of boys have abandoned school. There is still a significant issue of concern "Apparently what is happening to these Roma children inside the school is still far from the public commitment of the educational institution that is: offering equal developing opportunities to all children regardless of the colour of their face".(Nikolovska, 2008).

\section{The Roma education and employment in Albania}

"Before the World War II the lack of education and illiteracy used to be dominant characteristics of the Roma community. Education approach was rare because of the nomadic tradition and the school range in Albania at that time. Their conditions have improved during the socialist system when the educational system developed into a more universal system. Even though, they benefit from the basic education not being able to approach higher level of education. It is believed that during the post socialism transition the lower average school enrolment led the way to the deterioration of the education quality of the Roma people. (INSTAT, 2011) 
Various studies have provided many factors related to the low rate of education of the Roma people such as, low level of qualification of teachers in order to work with minorities, poor financial condition, high level of discrimination of the Roma community and frequent movement. (Gedeshi, 2010).

The Roma children achievement is far more unsuccessful than that of the other children. Besides the mentioned factors, irregular school attendance has an immediate impact on the Roma student's achievement. "Around $34 \%$ of the Roma children have confirmed that they have been absent from school at least once or twice during the last two weeks."(MAS, 2015).

"Given that education is neccessary to face the competitve labour market it is important the Roma children attend compulsory education and then some of them can study all the following levels of study by taking into account the ability to soften all barriers. From this point of view, the teacher's competency for inclusion has to include an overall pedagogy which proves that when deciding on the informatve teaching the individual characteristics of the children shall be considered teaching outside the school setting, existing knowledge of the student, individual and cultural experiences and interesests." (Florian \& Rouse, 2009).

Often, the Roma children's disadvantages are not compensated due to discrimination and failure to benefit from school: "they start their life with the poorest unemployed parents who underestimate the role of schools; children who lack parental support time to time are obliged to help their parents. They are obliged to study in a serious school which provides very little opportunities to live a funny and active life, etc.(Tamo \& Karaj, 2007)

If we consider children of all ages, the average percentage of school non-attendance in Albania is $3 \% .49 \%$ of the Roma children have never attended school. When parents send their children to school, they ask for the teachers' support as they confess they are uneducated themselves. When they have studied $2-4$ years they do not consider themselves uneducated. Especially the mothers who have the duty to look for their chidren nad assist them with their homework, confess that they do not know how to write and read. The approach toward education is challenging and directly affects their education level. If we refer to there are $96 \%$ of Albanian children who have completed the cycle of primary education from grade 1 to $4,80 \%$ of whom have reached grades from 5 to 9 , only $43 \%$ of the Roma students $(40 \%$ women and $46 \%$ men) who have completed the first four years of elementary school, $21 \%$ from whom have made it to the next for years of elementary school $918 \%$ women and $2 \%$ men).(UNDP, 2011).

"Poverty leads to more frequent cases when children are asked to work instead of go to school. They participate in informal economic activities of their families. When asked whether this was acceptable or not, $55 \%$ of the answers of the Roma people agreed, compared to the $25 \%$ of the Albanians."(UNDP, 2011)

"The main income for $40 \%$ of the Roma families comes from informal activity like collecting and selling rubbish. If we nclude the Roma people who declare that ther main income comes from informal employment in the private sector $(10 \%)$ ad those who declare their main income comes from casual employment (daily-based work, $11 \%$ ) the result is that the main income for $61 \%$ of the Roma families is based on the private sector. (Fondacioni Shoqëria e hapur për Shqipërinë, 2012)

The high school approach is a major challenge for the Roma students. The critical situation in education leads to a more critical status within the labour market. "There is evidence that $81 \%$ of the Roma people do not have a job, $9 \%$ of those have a profession whose demand is falling, and only $6 \%$ have a job in demand."(Fondacioni Shoqëria e hapur për Shqipërinë, 2012). The level of employment and unemployment highlight the low level of activity of the Roma people. The level of unemployment of the Roma women is reaching peaks of $58 \%$. The Roma people being employed in those jobs of low quality, serves as an evidence to their employment hrough the informal sector. (UNDP, 2011).

The right to education in the Republic of Albania shall be guaranteed to the Albanian

citizens, foreign citizens and those without citizenship, without discrimination in

terms of gender, race, colour, ethnicity, language, sexual orientation, political or

religious convictions, economic or social status, age, residing location, disability or 
other grounds being referred to in the Albanian legislation. The effective Albanian legislation aims at being aware, respecting, protecting the national identity and developing the cultural heritage;(Law 69/2012, 2012). Even though the allinclusive nature is within the previous strategy of the pre-university education already, the researches show that: not enough attention has been paid to the low results of the Roma children at school.

\section{The effort to transform the social, economical and education reality of the Roma community}

In 2005 , the countries taking part in the Decade of Roma commited in closing the gap between in welfare and living conditions between the Roma and non-Romapopulations, as well as putting an end to the cycle of poverty and social exclusion that many Roma find themselves in. Each of these countries has developed a national Decade Action Plan that specifies goals and indicators in the Decade's priority areas: education, employment, health and housing.(UNDP, 2011)

After more than 20-years of post-communist transition, local, national and international institutions have failed to provide a full database of Roma in Albania, despite several efforts and continuing financing. In absence of realistic information on Roma status, it is impossible to formulate adequate policies, to adopt effective strategies and to efficiently implement priority actions. It is also not efficient to provide financing for resolving Roma problems. As a result, it is strongly recommended to restart efforts by the collection of information; a specific registration of the Roma community seems to be indispensable and unavoidable.(Shoqëria Civile, 2012).

There is a general feeling that the Roma children are welcomed at school, which proves that exclusion and discrimination shall not be considered as the reason of not enrolling at schools. This interferes with the experiences given in the report of need assessment, in which between the different mentioned barriers to education, there is also discrimination and stigma caused by poverty are recognized as the main reason for avoiding school. The education system reform in Albania has led to clear qualitative changes as referring to the structure and content of the system, including education programs and teaching methodologies. Even though, yet the scholar texts do not provide any information on the Roma history and culture. The Roma community is referred to as a linguistic minority only in the scholar programs focused on the human rights issues together with the other ethnic and linguistic minorities without offering specific information on this community.

\section{Attempts to change the social-economic and educational reality of the Roma community}

In 2005, the governments joined the Roma decade committed themselves to narrow the gap that exists in the welfare and living conditions of the Roma as compared to the non-Roma population, take measures to reduce poverty and combat social exclusion in which many Roma find themselves all participating countries developed National Decade action plans, which specify the goals and indications in the areas of priority for the decade: Education, Employment, Health and Housing.(UNDP, 2011)

Despite several attempts and continuous financing, after more than 20 years of post-communist transition, national and international local institutions have failed in submitting the full records on the Roma community in Albania. In absence of real information on the Roma situation it is impossible to implement proper policies, approve effective strategies and effectively implement certain measures. This leads to a non-efficient attempt for financing for the Roma problems. As a result it is highly recommended the recommencement of financing for information collection. The specific registration of the Roma community is now necessary and inevitable. (Shoqëria Civile, 2012).

There is a general idea that the Roma children are welcomed at schools so exclusion and discrimination shall not be considered as a reason why they do not enrol at school. This is inconsistent with what is declared in the Needs Assessment, in which among the different barriers to education there is the discrimination and stigma caused by poverty which is identified as the main cause to school avoidance.

The education system reform in Albania has led to clear qualitative changes as related to the system structure and content, including teaching programs and methodologies. Still, there is no information on the Roma history and culture in scholar textbooks, yet. The Roma community is referred to as a linguistic minority in scholar textbooks which are concerned on human rights issues. No specific information is found for the Roma together with other ethnic and linguistic minorities. Time 
to time, models follow stereotypes, such as a piece of reading for the second grade student where the Roma student plays the accordion, but he/she is absent from class.

"The second chance program was approved by the ministry a few years ago appointing teachers for specific courses aiming the fulfilment of education gaps in the base education; aiming at encouraging them going back to school and preventing them from abandoning school. Despite the lack of regular statistics, the general perception of the Roma for this program is that it is a very useful and successful program and it should cover all schools including a big number of Roma children" (Shoqëria Civile, 2012).

Providing the Roma students with books according to the common Instruction number 51, clause 4.6 has made it easier for the students, but still there are some students that quit school a few weeks after starting. The Regional Education Director atehas offered several trainings on the new learning programs, new teaching methodologies for teachers.

Specific modules have been included within the training sessions for teachers working with vulnerable groups of students, especially Roma students. Additional trainings have been offered to teachers working with the Roma by the NGOs, financed by the international donator agencies" (Shoqëria Civile, 2012).

The report provides a general description without real figures. According to the questionnaires, the trainings covered just a limited number of modules and were offered to just a limited numbers of schools especially to those with a considerable number of Roma students

"Lack of motivation is one of the main answered reasons why the Roma students quit school. This means it is boring and unpleasant. What school provides them with, does not match to their real life and neither does it match to their future aspirations. In order to be motivated, they need stimulation, aspiration, influence and enthusiasm as it usual for children from the non-Roma families. They also need self-assessment, influence, work for an aim and understand that they have to do something valuable which usually teaching classes cannot make them understand (Shoqëria Civile, 2012).

\section{Multicultural Education and its value}

Multicultural Education is a process which goes through all aspects of the school practices, polices and organisations, as a way of reaching the highest academic achievement for all students. It helps to develop a positive self-assessment by showing knowledge on the history, culture \& contributions of various groups. It leads students to actively work towards structural equality in different organisations and institutions by offering their knowledge and skills to reapply power and income in different groups.

Intercultural Education is considered to be the tool which helps fight educational disadvantages of children with ethnic minority backgrounds(Leeman \& Ledoux, 2003). One from the sub-clauses of the Roma decade strategy was the improvement of qualifications for teachers: "Training sessions for teachers in the intercultural environment and periodic qualifications in relevant sessions."(UNDP, 2011, p. 14)

This is not about improving qualifications as nowadays it is a requirement for education which is an ongoing organism, but it is exactly about becoming qualified in multiculturalism or in the theory of multicultural education.

What is the multicultural education?

Multicultural education is a critical pedagogy based on experiences, knowledge and viewpoints of students and teachers. Multicultural Education promotes social rights. Many teachers believe that social rights can be cultivated within the classroom by assessing diversity, promoting equality, by bringing in a wide improvement of views, based on influence and free speech (Brooks \& Thompson, 2005). Practically this means making the necessary adaptations for those children with different special needs so as to provide equal lesson and assessment approach.

Multicultural Education is a developing and complicated process, important to all students, not only to coloured or disadvantaged students. This is racist. Multicultural Education is basic, which means that it is important in every aspect such as, reading, writing, and mathematics. It includes all aspects of school life, setting, curricula and relationships between teachers, students and the largest community of the school(Nieto \& Bode, 2008). Another concept is presented by Grant 
and Sleeter highlighting the fact that "Multicultural Education means having the faith that in a certain society, school can and has to prepare citizens to work in groups and be active in order to confront the problems which society might face" (Grant and Sleeter 2008).

Teachers from different schools were asked about their knowledge on multicultural education. The study concluded that the majority of the teachers had never heard about this philosophy, not even about its principles and dimensions. Some of them believed that this type of education would be helpful just in the areas around the borders or in classrooms with children from different nationalities.

Usually, the origin of school problems is the prejudicial nature of the humans and of teachers in general. This is why minimizing prejudice is the first goal to be achieved. The teachers will start to reduce prejudice, once they realize how much it affects teaching process. Multicultural Education is based upon 5 major dimensions, which make the root philosophy of this education, explaining its efficiency and success in all groups of students.

Prejudice Reduction: It is focused on the characteristics of the students' attitudes and how they can be modified through learning methodologies and information.

"Intergroup prejudice is a concerning issue which can be reduces through school education as they are public places where students can learn how to negotiate and how to apply the difference between the things they know. If the prejudice system will not be explored in schools the students will not have the chance to identify and reduce the intergroup prejudice.

Intergroup prejudice is turned to children from their families, school community or teachers who do not offer equal opportunities to improve their academic, mental and physical skills (Janaqi, 2013).

In such a circumstance students realize the existence of numerous social perspectives which offer social conditions to help improve their intergroup relationship at school and community." (Camicia, 2007).

Inclusion of content has to do with the application of different cultural examples and contents by the teacher in order to introduce key concepts, principles and generalisations in the subject field.

Teachers, being aware of the cultural diversity, try to understand the universal viewpoints of different students and respect and accept them as such. Educational Researches, even when they are traditionally focused on effective teaching and academic success, agree that the quality of education is partially defined by students individually, by the time and context and they recognize that the teachers' professionalism shall be focused more on the "diversity" and on the reflection of how the diversity approaches the teachers' education practice and the their actions based on this reflection(Leeman \& Volman, 2001).

The process of building up knowledge relates to the way in which teachers offer their support to students by helping them understand, look into and define cultural intended assumptions, reference frames and perspectives and prejudice within a discipline which has its impact on the ways knowledge is set up.

Grouping and Labelling practices, sports participation, in a disproportion with the staff and students, regardless of ethnic and racial diversity, are those components of school culture which should be examined in order to build that school culture which favours the development of students from different racial, ethnic and cultural groups. "Very often these factors completely cover the prejudice and the strong ignorance as referring to what it can actually be done in order to include a larger variety of children"(Musai , lkonomi , \& Sotirofski, 2009).

Equality between the pedagogical staff happens when teachers modify their teaching process in order to simplify academic achievement for students from different social classes and, cultural and racial differences. This includes a variety of types of learning processes applied to a wide variety of teaching process within different cultural and ethnic groups. (Banks, 2006).

Every student has the right to develop and study in a school close to his house. This is particularly included in the UNO convention on Children's Rights. It is true that their settlements are grouped in certain quarters especially in the outskirts usually next to the river shores. Around $12 \%$ of the Roma express their difficulty to access the school setting(INSTAT, 
2011). Therefore, several schools tend to have larger numbers of students from this community. Teachers have to be conscious of their specific role and how to adapt it while working with other multi-disciplinary professionals (social workers, psychologists and different therapists) in developing and applying the IEP, etc. (Musai , Ikonomi , \& Sotirofski, 2009, p. 54).

\section{The teacher, is a key factor in education's quality development}

Education goes through various challenges. Teachers and school will provide the needed support. In theory, teachers expect a lot of challenges, but are they ready to manage the reality of social, cultural and economic differences of this community? Are they able to meet the needed copetency without performing any qualification processes? Qualifications are essential to the teachers' constant adaption to the needs, especially when referring to new international theories.

"We have to pretend more than immediate academic achivement from our educators... and there won't be the minor success achieved if students, our children, won't beleive that educators love them and take care of them, even if they themselves won't know how to look for others."(Noddings, 1995) Noddings calls it a minor success the imediate academic success as compared to learnning how to look after each-other. She proceeds with her comment that taking the time to develop a positive relationship with the students, speak with them about their problems, help them become sensible and skilfull are very important educational activities. These kind of relationships are very important as they encourage learning, which might be very difficult to achieve through other ways.

There are several procedures and institutions providing multicultural programs' accreditation. Continuous training programs are opptional and they are not available to all teachers. Currently there is lack of awareness of the wide range of dversity between the students. (Musai , Ikonomi , \& Sotirofski, 2009, p. 36). Therefore, helping the diversity and mechanisms which can develop the teachers' qualificatins and trainings does not give any hope.

Proffesors from the NCTI or the local authorites and other state agencies, usually bear the official status, but these accreditted institutions do not apply prorites on community qualifcations. This study shows that teachers are interested in different trainings in order to raise their credits, eventhough the training theme dos not fit. Moreover, the training sessions are charged therefore teachers are not interested in them. Specific theme tranings are ofered by NGOs which might not meet the teachers needs but do match to their plans and visions. The NGOs' professors are higly motivated and qualified.

Teachers say that, "We would like to attend various training sessions but they are too expensive to be afforded. We are lucky if offered any training sessions by the NGOs".

Teacher A describes, "These kind of training sessions are highly efficient especially for us who don't have many experiences at work. Often it seems like we lack the proper proficiency or it's like the students are unable to learn. But i do understand now that this is not true. All i learned was helpful and i could see the problem from e different point of view."

Teacher B, "Even if you have a lot of years of xperience, often you have to reconsider your attitude during the class session. For example, I was surprised to face that positive reaciton from the sudent's parent and to see that my teaching would make him feel delighted in front of his classmates."

Teacher $\mathrm{C}$, "We often believe that in order to make students understand the lesson we have to spend too much effort while teaching, but no. If you use different games, you achieve more than you can imagine."

Teacher D, "Gandhi quotes - If you want change, starts with yourself. If I will think differently, it will have my impact on others also. I could assure that the only thing these students need is a little more love than the others. Probably because of their hard living conditions. They need more affection. I have been working with at least 10 Roma students and I have been delighted. So they have been successful."

Teacher E, "We may need to consider time, and give more time to the changes. I cannot forget the example of the professor and the candle: if we light the candles one by one, no one will notice, but if we light 5 or 6 at a time, there is a difference."

Teacher F, "They say, You Live and Learn, so it is not enough. Despite going through a long experience, us, the old generation tend to ignore the gender difference. Even if we do not agree with anything, we do not have why to offend them, not even indirectly." 
In 2016, for the first time it was issued a national report indicating the teachers and directors' needs as referring to the preuniversity education. Our responsibility towards 500,000 students and their parents is based upon this document, showing reality, bearing the name of every teacher, school, Regional Education Directorate. But the important thing is being engaged in time, with measurable indicators in order to improve the urgent issues and after that to build a permanent, coherent system for the teachers' qualifications." (MAS, 2016)

"These agencies have not had a proper cooperation and coordination with the Regional Education Directory and schools in order to provide real support which meets the reforms of the pre-university system. Very often, the media or several teachers have reported a very negative side of the education system, delaing for credits. There is also lack of the professional literature and publications to support teachers to learning about development, following the experiences of their local and foreign colleagues. Meanwhile, the online courses are missing also."This was cited in the report, adding that there was a poor coordinaton between the university education as referring to the teacher's qualifications."(MAS, 2016)

"The national report for the identification of the teachers and directors' need for trainings" identified the need for qualification based on the analysis of subjects referring to the general standards of the teacher. Each subject includes several issues which lead to the tools which help identify what's needed, as follows:

Planning (annual, daily planning) etc. Planning according to the students' needs (learning objectives or results, learning resource, Planning real-life cases, ensuring coherence of planning, planning the assessment tools). Teaching and Learning (the methodology of teaching-learning), Learning assessment, the question technique and discussions, (manage the classroom and the students' behaviour) the physical environment of the classroom, Classroom climate, Communication and Ethics, Ethics Code, communicating with the Students, Communicating with the parents, Communicating with colleagues, collaborating with the community, professional development, participating in professional development activities, participating in professional networks.(MAS, 2016)

Important elements such as social equality and prejudice have not been analysed, although they can help identifying various elements helpful to multicultural education.

EDI has accredited teachers according to Directive 26 date 15.08 .14 based on Article 58, Law no. 9754, "Social Justice Education" program which has a key role in multicultural education. NGOs related to and interested on the Roma community problems, have been analysing and offering this to teachers.

Even after a few sessions of qualification, you can feel the difference in their attitude towards themselves and the student. This was identified during the interviews with the teacher.

\section{Methodology}

Theoretical support of the study is based on the study of literature and educational policies reported by the Ministry of Education and Sports.

This is a case study which refers to an infrequent example. The semi-structured interview is the key instrument applied with, Teachers; Students; Parents

\section{School Directors}

The semi-structured format of the interview is mainly based on key questions which are included within the study, the vocabulary used is simple and familiar to the participants of the study. This is followed by study surveys related to the feelings and benefits from the "social justice" training and how much does this help training and working with certain categories of children, especially those from the Roma community.

The questionnaire aims at identifying the popularity of multicultural education and making clear if prejudice is preventing the teaching process and if so, at what extent. It tends to find out in which areas do we need to intervene in order to make teachers conscious about the importance of considering all students equally and minimizing prejudice. 
When asked if they are prejudicial to others, $90 \%$ of teachers answered "No", but the following answers reveal the prejudging nature of their actions. For example, when asked to whom would they firstly give a certain task, to boys or girls, to children with a good economical background or not, to a Roma student or to the majority, we could understand that they were very prejudicial to others according to their answers. (We keep in mind here the people's sincerity also).

Teacher 1 says, "I have organized the cleaning groups with both boys and girls, but the boys will carry the water and throw the rubbish away, girls will clean...".

Teacher 2 says, "The Roma parents, are not interested at all and they do not come here along the year, so in the front desk will be sitting those whose parents come to school and ask about them".

Teacher 3 says, "The desk does not make the student, but the Roma students usually stay in the last desk as some are older than the others while some others prefer doing so".

Teacher 4 says, "When students are asked to bring some school tools with them, the Roma bring just a few so they work with fewer tools than the others".

So, it is not the principles which reflect on behaviours, but the demand and interest of certain groups.

\section{Findings}

According to the study, teachers from different schools had the following knowledge on multicultural education: the majority had never heard about such a philosophy, neither for principles or dimensions. Some of them believed that this type of education was used just in areas near to the borders or in multi-nations classrooms.

Less prejudice is the key to multicultural education which has a clear impact on the process of teaching. As soon as teachers come to know this factor, they will become conscious of its importance and will try to avoid it. Equal society education makes the teacher self-confident about his professional skills and improves his efforts for better results.

\section{Study Restrictions}

There are no standard questionnaires in this study, but it is based on different questionnaires and supporting theories. The number of teachers was limited also and not all questions were asked to the same groups of people. All teachers work with Roma students but the choice was casual. They were selected intentionally as part of organized trainings.

Not all questionnaire answers were included within the study. 